\title{
Concerns about Diabetic Foot Wounds
}

\author{
Denis E. Solomon \\ 9B Somerville Road, Wigan, Lancs, England \\ Email: denissolomon@yahoo.com
}

How to cite this paper: Solomon, D.E. (2019) Concerns about Diabetic Foot Wounds. Open Journal of Regenerative Medicine, 8, 1-4.

https://doi.org/10.4236/ojrm.2019.81001

Received: February 9, 2019

Accepted: March 28, 2019

Published: March 31, 2019

Copyright (C) 2019 by author(s) and Scientific Research Publishing Inc. This work is licensed under the Creative Commons Attribution International License (CC BY 4.0).

http://creativecommons.org/licenses/by/4.0/

\begin{abstract}
This paper in a medical sense can be described as a case report. The diabetic foot wounds of a relative, over 70 years of age, with Type I diabetes were so grievous and the medical treatment was so protracted that success could not be assured. There was a danger of amputation. The one outstanding feature was that the private application of an antifungal spray, between the toes of both feet without prescribed oral mycologic agents, seemed to make an inexplicable difference to the final outcome. In addition, a viewpoint drawn was that the efficacy of antibiotic therapies may be compromised by the presence of invisible fungal etiology.
\end{abstract}

\section{Keywords}

Type I Diabetes, Wounds on Soles, Anti-Fungal Spray, Light Weight

Dressings, Efficacy of Antibiotic Therapy

\section{Introduction}

This paper resulted from an unexpected series of events. I was idly reading a review by Wukich et al. (2013) [1] and saw a photograph of a foot wound in their Figure 2 and its legend entitled "Photograph of patient with a severe, limbthreatening necrotizing diabetic foot Infection". To my eyes, there was a fungal infection present, superimposed on the toes, but when I searched the paper for mycologic agents used in treatment, I could find none. Intrigued, I conducted a literature search using the phrase "cultures of diabetic foot wounds with fungal infections". PubMed (NIH) search engine could only supply seven published articles. The latest was an article by Ozurk et al. (2019) [2] seeking to highlight the neglected causative agent of fungal etiology in diabetic foot infection.

In ageing human skin, elastin contained in the reticular dermis has a half life of 74 years Weiss (2011) [3] and with its loss, skin becomes more fragile. The craggy facial appearance of the elderly (over 75s) is a direct result. Add auto- 
nomic neuropathy and dry skin, more susceptible to cracking Holloway (2019) [4], to the mix and healing becomes more of a problem because of the reduced production of dermal fibroblasts and collagen resulting in a diminished reticular dermis. These points should be taken into consideration because the normal skin structure of earlier life is not present anymore. Instead, it is diminished and thin and vulnerable to both bacterial and fungal infection; the latter from the cracking skin between toes. Therefore, the medical pursuit of only bacterial infection with the use of antibiotics needs careful reconsideration. At present, it is not known whether fungal infection impedes the efficacy of antibiotics, but as will be described below, the targeted application of an antifungal spray seemed to cause some amelioration of the wounds. Because of patient confidentiality, I cannot list the prescribed medications, but it must be assumed that standard medical care was applicable.

\section{Discussion}

The background to my interest in diabetic foot wounds was aroused by an elderly relative with Type I diabetes with quite grievous wounds on the soles of both feet (See Figure 1). She was morbidly obese and needed a walking aid. For years, she was wheel chair-bound or in bed. One foot infection had spread to her ankle and there was clearly observable tissue degradation. Attending nurses at one hospital had expressed the real possibility of amputation.

I had visited her at three major hospitals and four nursing homes in the State of Louisiana, USA over a six-year period and had silently observed the complete failure of debridement, offloading, glycaemic control and concomitant antibiotic therapy. As a last resort, she sought maggot therapy at a specialist hospital. This treatment had an immense and impressive effect of cleaning and sealing the wounds with a thin layer of epidermis and her ankle area healed quite rapidly. Unfortunately, immobilisation for six weeks did not immediately follow (to allow keratinisation) and the wounds on the soles of her feet reopened. She was attended at home by a nurse who changed her dressings twice a week. There was continual offloading and glycaemic control. There was no medical prescription for a mycologic agent. However, a personal decision was made to deploy an over-the-counter antifungal spray named Lotrimin ${ }^{\circledR}$ containing $2 \%$ miconazole nitrate to counter any present Candida species between the toes and possibly elsewhere within the cracked skin. This was applied once a day, for four months, excluding those two days per week when her home nurse attended. The manufacturer provides a warning on the can's label that the spray is intended for external use only. However, when this spray is used on cracked skin between the toes it will become invasive. In the opinion of the home nurse, wounds became stabilised and seemed to improve after the application of the spray. Wound management with normal dressings continued as before. The one difference was that a light bandage, with applied antifungal cream on one side, was looped between the toes of both feet and refreshed appropriately. 


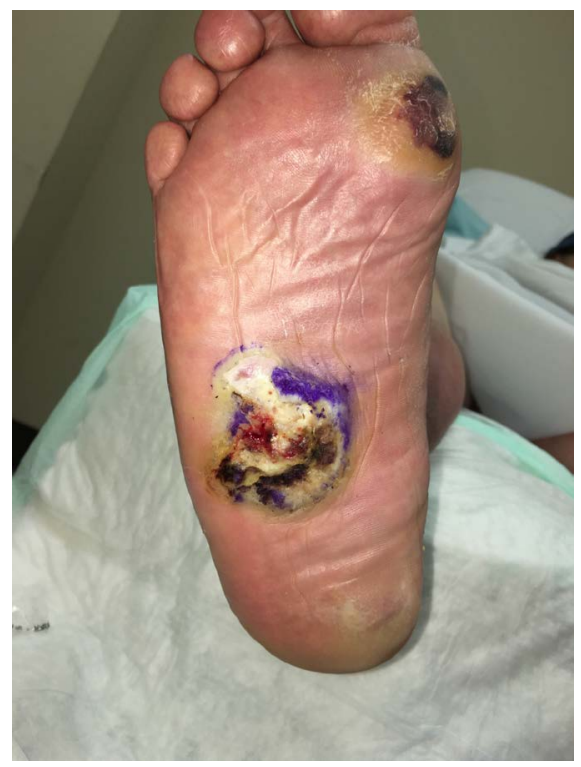

Figure 1. Diabetic wound on sole of one foot. The other foot had a comparable wound on the sole.

Fluconazole $150 \mathrm{mg}$ is the normal oral medical prescription for fungal infection, as described by Chellan et al. (2012) [5] because it is believed that this medication works efficiently. This paper dares to suggest that additionally, an antifungal spray should be directed between the toes to provide a preventative seal to ageing, cracked skin brought about by autonomic neuropathy.

Bed bound after a cerebral stroke, with a calorie-controlled diet and regular checks of blood sugar levels, wound care continued. This author had observed a variety of applied dressings at different hospitals and nursing homes over the years, which to my eyes were weight bearing and inappropriate. I mused that if attending physicians had seen under the microscope, stripped human epidermis disassembling into epidermal rosettes (Solomon 2012) [6], they would not sanction weight bearing dressings and sponges (to absorb seepage) on any cutaneous wound including pressure ulcers. At her post-stroke nursing home, a small blue non-adhesive pad was applied, sealed over with a transparent tape and an ankle length flimsy stocking with open toes was overlaid. After 3 short months, her wounds were fully healed. It was observed that the diameter of her wounds decreased to a fraction of their original size, before finally being completely healed. At no time over the years, was venous hypertension mentioned.

\section{Conclusions}

My relative's wounds on the soles of her feet completely healed which gives a lie to the medical mantra that "diabetic wounds do not heal". The spray, as opposed to a skin cream, could quickly penetrate and target any deep seated area of unknown fungal infection, thereby allowing prescribed antibiotics to exert their fulsome effects. This conclusion is inevitably drawn after the failure of a range of antibiotic therapies (some were culture-specific undoubtedly) over several years. 
Research is needed to confirm that fungal infections should be assuaged, before standard antibiotic care is prescribed. Also, whether the medical dependence on oral mycologic agents can be undisputably justified (that is, do they reach the target areas?) and when exactly they should be prescribed for immediate use. Finally, there is an outstanding question. In a last ditch attempt to prevent amputation, did the attending physicians consider placing a bag of medical maggots over the necrotizing tissue shown in Figure 2, Wukich et al. (2013)? It should be noted that there was no looped bandage between the toes, as was described earlier.

Diabetic wounds present an ongoing challenge to attending physicians. It is to be hoped that this paper makes a small contribution to the future success of healing of diabetic foot wounds.

\section{Conflicts of Interest}

The author declares no conflicts of interest regarding the publication of this paper.

\section{References}

[1] Wukich, D.K., Armstrong, D.G., Attinger, C.E., Boulton, A.J.M., Burns, P.R., Frykberg, R.G., Hellman, R., Kim, P.J., Lipsky, B.A., Pile, J.C., Pinzur, M.S. and Siminerio, L. (2013) Inpatient Management of Diabetic Foot Disorders: A Clinical Guide. Diabetes Care, 36, 2862-2871. https://doi.org/10.2337/dc12-2712

[2] Ozturk, A.M., Tasbakan, M., Metin, D.Y., Yener, C., Uysal, S., Yilidirim, S.I., Erlam, I., Pullukcu, H., Arda, B. and Cetinkalp, S. (2019) A Neglected Causative Agent in Diabetic Foot Infection: A Retrospective Evaluation of 13 Patients with Fungal Etiology. Turkish Journal of Medical Sciences, 49, 81-86. https://doi.org/10.3906/sag-1809-74

[3] Weiss, A.S. (2011) The Science of Elastin. Elastagen Pty Ltd., 1-8.

[4] Holloway, S. (2019) Skin Considerations for Older Adults with Wounds. British Journal of Community Nursing, 24, S15-S19. https://doi.org/10.12968/bjcn.2019.24.Sup6.S15

[5] Chellan, G., Neethu, K., Varma, A.K., Mangalanandan, T.S., Shashikala, S., Dinesh, K.R., Sundaram, K.R., Varma, N., Jayakumar, R.V., Bal, A., Kumar, H. (2012) Targeted Treatment of Invasive Fungal Infections Accelerates Healing of Foot Wounds in Patients with Type 2 Diabetes. Diabetic Medicine, 29, e255-e262. https://doi.org/10.1111/j.1464-5491.2012.03574.x

[6] Solomon, D.E. (2012) Mimicry of a Natural, Living Intra-Epidermal Micropattern Used in Guided Tissue Regeneration of the Human Epidermis. Journal of Developmental Biology and Tissue Engineering, 4, 1-7. https://doi.org/10.5897/JDBTE11.023 